MATEC Web of Conferences 40, 05007 (2016)

DOI: $10.1051 /$ matecconf/20164005007

(c) Owned by the authors, published by EDP Sciences, 2016

\title{
Experimental Research about Thermal Capacity Difference between Domestic and Foreign Plate Heat Exchangers
}

\author{
Ruihang Zhang ${ }^{1}$, Jingdong Chen ${ }^{1}$, Runping Niu ${ }^{1}$ \\ ${ }^{1}$ School of Environment and Energy, Beijing University of Civil Engineering and Architecture, Beijing, China, 100044
}

\begin{abstract}
Because of the noticeable advantages of plate heat exchangers compared with tube heat exchangers, it has been widely applied and researched. However, in the process of practical application, it is easy to find that the performance of heat exchangers produced domestically and from developed countries are quite different, which is one of the key factors that restrict the wide application of domestic plate heat exchangers, there are few studies on this subject yet. Thus, the paper analyzed the main difference of thermal capacity between a domestic and foreign plate heat exchangers through experimental researches, and the results all show that, foreign plate heat exchangers has a more superior thermal capacity and heat exchange efficiency than domestic one, which is in purpose of offering some guidance on technical improvements and applications in the future.
\end{abstract}

Keywords: Domestic; foreign; heat exchange efficiency; plate heat exchanger; thermal capacity

\section{Introduction}

With the development of science and technology and the emergence of the world energy crisis, plate heat exchanger is gradually getting more attention and researches in the field of heat ventilation and airconditioning. Compared with shell and tube heat exchanger, it is superior in its simpler structure, smaller volume, lighter weight, higher heat transfer efficiency, lower fouling coefficient, wider range of application and so on. Thus, the technology of plate heat exchanger is becoming more and more mature in re-cent years, and it is widely used in all walks of life, especially in the field of cooler air-conditioner.

The emergence of stainless steel corrugated-type plate heat exchanger in 1930 opened a new era of modern plate heat exchanger, and a lot of researches have been done from different angles after that. Afonso et al.[1] discussed the entrance effect on local heat transfer coefficients through experiment; Wamakulasuriya and Worek[2] researched the characteristics of a commercial plate heat exchanger during cooling processes; Jeong et al.[3] studied the performance of plates of three different types of welded plate heat exchangers. Zhao[4] systematically re-searched the influence of ripple angles on plate heat ex-changers. Ma et al.[5] measured the resistance features of two different plate heat exchangers under the condition of low Reynolds number $(200<\operatorname{Re}<1300)$. Muley and Manglik[6] obtained a series of comprehensive relation of heat transfer and flow resistance through experimental analysis. In addition, Ren et al.[7] researched enhanced heat transfer of high dry degree fluid, and made sure the correlation of heat transfer coefficient with rate of flow, pressure drop and flow rate. Overall, the previous researches of plate heat exchanger mainly concentrated in following aspects [8]: developing efficient corrugated plate, developing plate applied to corrosion medium, developing large-scale plate heat exchangers, finding ways to improve working pressure and temperature, as well as researching the phenomenon and mechanism of heat transfer and flow behavior of plate heat exchangers.

In fact, though plate heat exchanger has been widely used abroad since the 1930s, our country hasn't produced it and applied it into the field of central heating until the 1980s. Thus, gaps of product quality and its heat transfer coefficient at home and abroad still exist, which will certainly lead to some degrees of confusion in the process of type selection. However, little attention was paid on this topic. So, concerning this issue, experiments are accomplished in the difference of heat transfer coefficient of the same type of plate heat exchanger.

\section{Experiment device and conditions}

\subsection{Experiment Principle}

\subsubsection{Test principle}

The difference of thermal properties of the two different heat exchanger mainly performs in two states: one is transient heat transfer and the other is steady-state heat transfer. 
Transient heat transfer means the temperature-rise curve of test specimen. The heat exchanger performance is judged based on temperature-rise curve of the reverse side of the heat exchanger. As shown in Fig. 1, the property of temperature-rise curve $\mathrm{A}$ is better than $\mathrm{B}$.

Steady-state heat transfer is a process of heat exchanger's reaching to a steady state under the given heat load (heating power), which can be simplified to a process of thermal conductivity of a tablet. It is as shown in Figure.1.

According to Fourier law:

$$
\Phi=A \frac{\lambda}{S}\left(T_{1}-T_{a}\right)
$$

Where $\Phi$ is heat exchange amount, $\mathrm{W} ; \mathrm{A}$ is heat exchange area, $\mathrm{m} 2 ; \lambda$ is thermal conductivity, $\mathrm{W} / \mathrm{m} \bullet \mathrm{K} ; \mathrm{S}$ is slab thickness, $\mathrm{m}$; $\mathrm{T}_{1}$ is inner wall temperature, $\mathrm{K}$; Ta is outer wall temperature.

It can be analyzed that, in the condition of same heat exchange amount and same structure size, the higher the coefficient of thermal conductivity of the tablet is, the higher the temperature of outer wall of the plate is, and vice versa. As is shown in Figure.1, the property of testpiece $\mathrm{Ta}$ is better than $\mathrm{T}_{1}$ in the two temperature distributions.
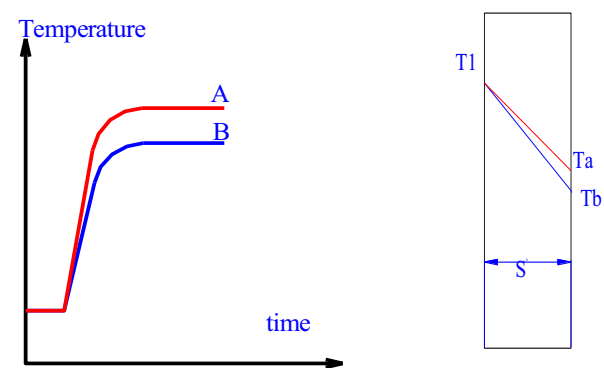

Figure.1 Heat transfer sketch (a) Transient (b)Steady-state

\subsubsection{Principle of measurement of thermocouple}

A close loop is formed after welding two different kind of metal conductors together, and thermoelectric emfs is produced in the loop when heating the sealing end (measuring terminal), this phenomenon is Seebeck-effect. Thus, based on this phenomenon, the temperature of measuring element can be got through measuring thermoelectric emfs when thermocouple materials and reference temperature $\left(0^{\circ} \mathrm{C}\right)$ is fixed.

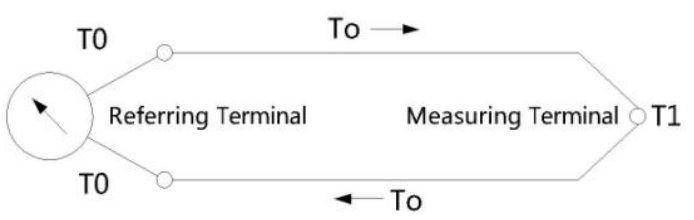

Figure.2 fundamental diagram of thermocouple

\subsection{Thermal measurement system}

Infrared thermometry and thermocouple thermometry are used as two complementary and mutual authentication to test the temperature distribution in purpose of making sure the accuracy of test results. Seen from Fig. 3-5, it is clear that the whole thermal measurement system includes infrared thermometry system, thermocouple thermometry system, and electric heating system(heating film, voltage regulator, multimeter). Voltage regulator and multimeter were used to readjust the heating power $\mathrm{P}$ of aluminum heat exchangers and the test heating voltage $\mathrm{U}$ of electric heating film, respectively. The resistance of heating film $\mathrm{R}$ was measured in advance. So the heating power $\mathrm{P}$ of heating film can be got through equation:

$$
P=U^{2} / R
$$

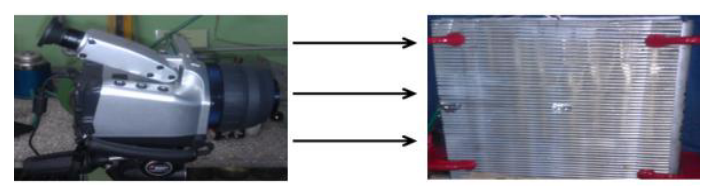

Figure.3 Testing schematic of infrared thermal imager

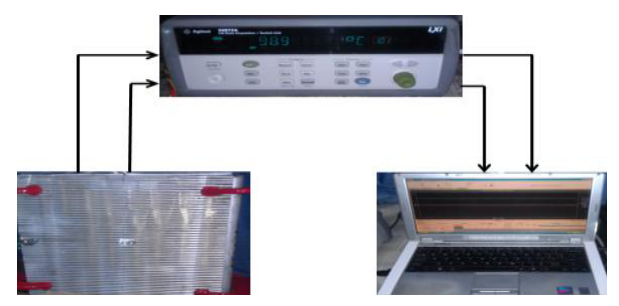

Figure.4 Testing schematic of thermocouple

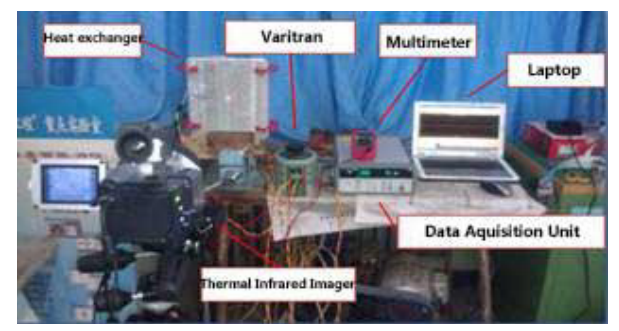

Figure.5 Thermal measurement system

\subsection{Layout of thermocouple testing point}

As is shown in Figure.6(a-d), there are two testing points located in the center of inner and outer side of plate of heat exchanger respectively. Heating source is produced by the voltage of both ends of plate. Insulation cotton is set between hot plate and fixed plate for the sake of preventing heating source from passing heat to the side of fixed plate.

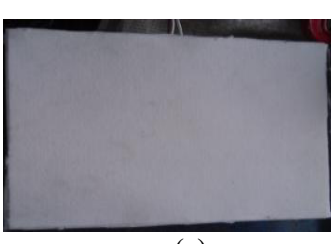

(a)

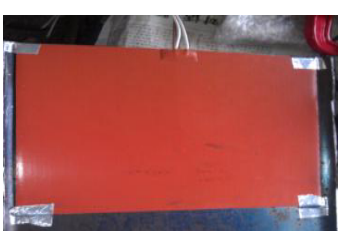

(b) 


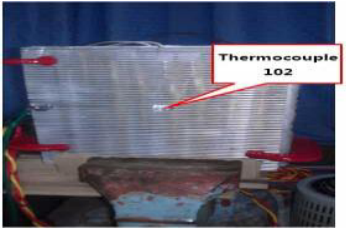

(c)

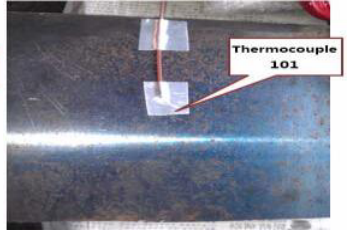

(d)
Figure.6 Layout of thermocouple testing point: (a) Insulation cotton; (b) Heating plate of resistance wire; (c) Outer thermocouple of heating plate; (d) Inner thermocouple of heating plate

\subsection{Test conditions}

This test chose $100 \mathrm{~V}, 80 \mathrm{~V}$ and $60 \mathrm{~V}$ as the test voltage, and the corresponding power is $60.02 \mathrm{~W}, 38.42 \mathrm{~W}$ and $21.61 \mathrm{~W}$ respectively. The total number of tests is 6 . After each test, heat exchanger was cooled below the environment temperature, and will not continue to work until they come back to a consistent state. Through the whole process, thermal infrared imager was used to record the surface temperature change at regular intervals. The test ended when the temperature reached stabilized.

\section{Results and discussion}

\subsection{Thermocouple test results}

The measuring point inside and outside the heat exchange plates is point 101 and 102; A and B represents domestic and foreign heat exchanger models respectively.

\subsubsection{Test results at $100 \mathrm{~V}$}

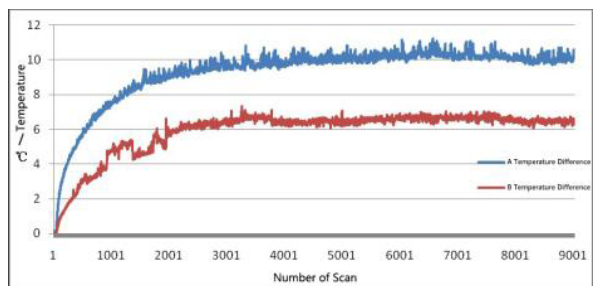

(a)

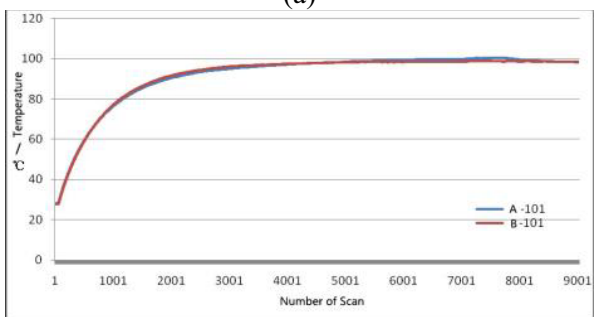

(b)

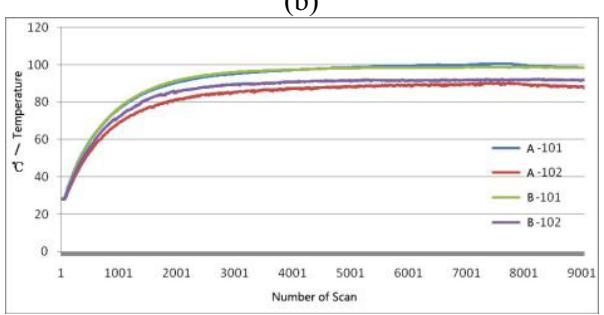

(c)
Figure.7 Comparison of Temperature between A and B at 100V: (a) temperature difference bilaterally; (b) interior temperature change; (c) temperature change bilaterally

\subsubsection{Test results at $80 \mathrm{~V}$}

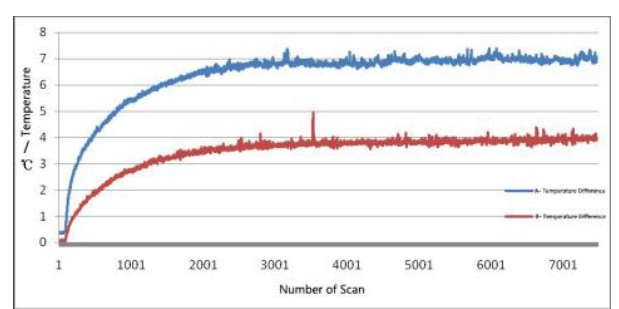

(a)

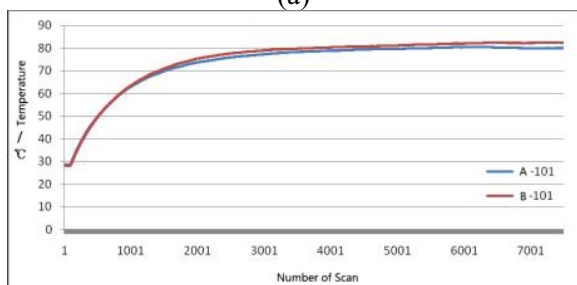

(b)

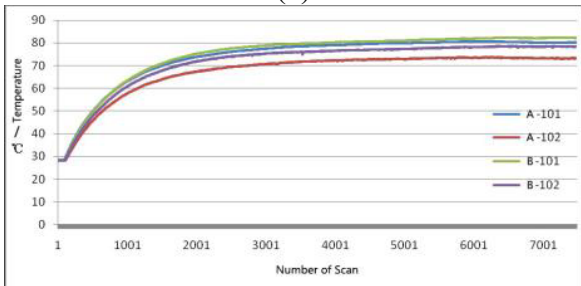

(c)

Figure.8 Comparison of Temperature between $\mathrm{A}$ and $\mathrm{B}$ at $80 \mathrm{~V}$ : (a) temperature difference bilaterally; (b) interior temperature change; (c) temperature change bilaterally

\subsubsection{Test results at 60V}

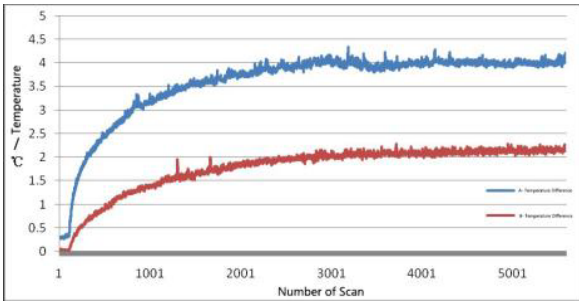

(a)

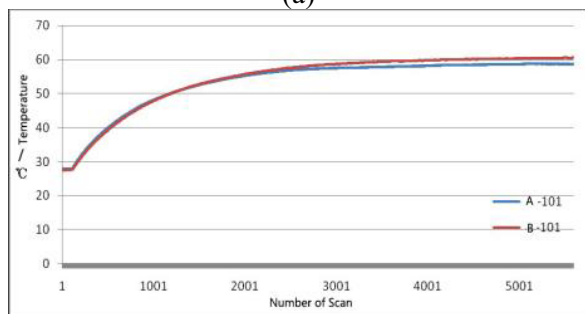

(b) 


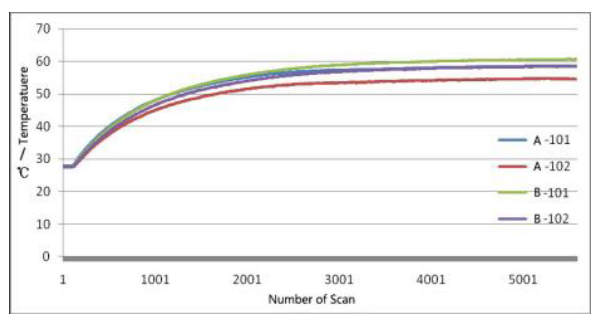

(c)

Figure.9 Comparison of Temperature between $\mathrm{A}$ and $\mathrm{B}$ at $60 \mathrm{~V}$ : (a) temperature difference bilaterally; (b) interior temperature change; (c) temperature change bilaterally

\subsection{Infrared thermography test results}

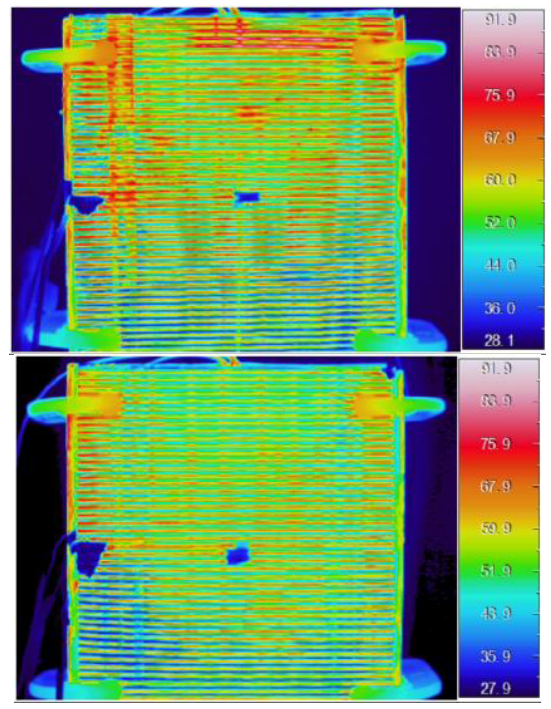

Figure.10 Outside temperature distribution of $\mathrm{A}$ and $\mathrm{B}$ heat exchanger at $100 \mathrm{~V}$

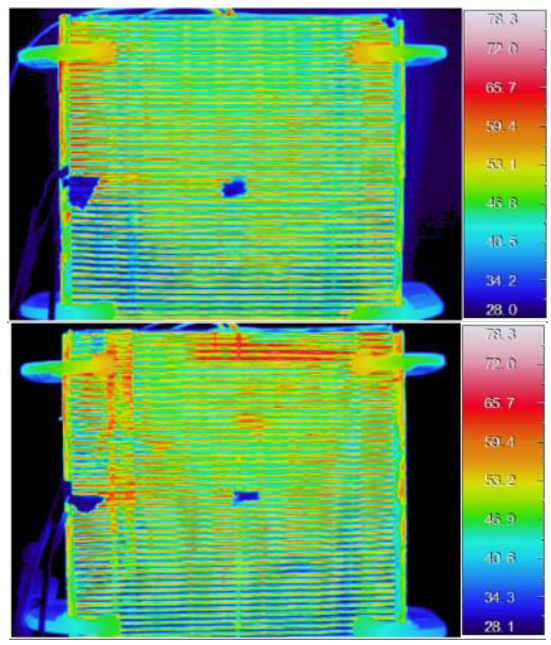

Figure.11 Outside temperature distribution of $\mathrm{A}$ and $\mathrm{B}$ heat exchanger at $80 \mathrm{~V}$

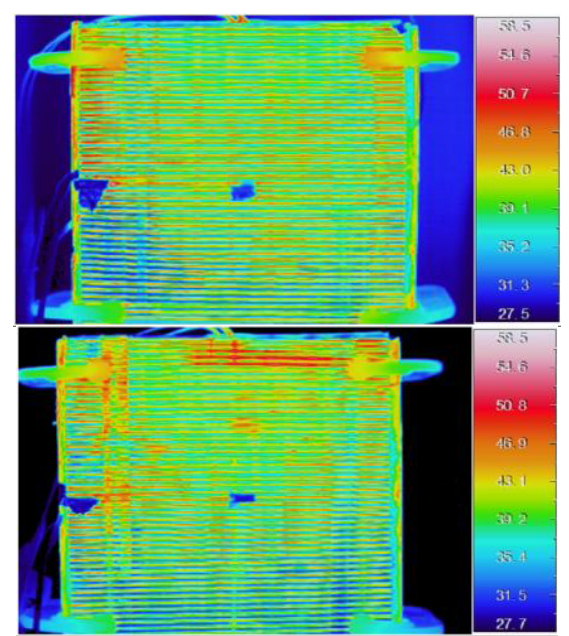

Figure.12 Outside temperature distribution of $\mathrm{A}$ and $\mathrm{B}$ heat exchanger at $60 \mathrm{~V}$

In Figure.10-12, there are two different results worth to be discussed:

(1) The overall temperature distribution is uniform, temperature in the position of central part and heat transfer film is much higher, which due to its minimum outside interference.

(2) A and B heat exchanger shows the same rule at three different voltages. Taking the highest voltage $(100 \mathrm{~V})$ as example, the highest outside temperature of domestic and imported heat exchanger is $82.7^{\circ} \mathrm{C}$ and $91.9^{\circ} \mathrm{C}$, which further high-lights the fact that imported heat exchanger has a better thermal efficiency than the domestic one.

\section{Conclusion}

According to two principles of transient and steady-state heat conduction, the thermal conductivity of B and A heat exchangers at three different voltages are tested through thermocouple and infrared thermography tests. It can be concluded that:

(1) The difference of steady-state temperature decreased with the decrease of voltage of heating plate. As is shown in the following table 1:

Table 1 Difference of steady-state

\begin{tabular}{ccc}
\hline Voltage $(\mathrm{V})$ & $\begin{array}{c}\text { Temperature } \\
\text { difference of A }\left({ }^{\circ} \mathrm{C}\right)\end{array}$ & $\begin{array}{c}\text { Temperature } \\
\text { difference of B } \\
\left({ }^{\circ} \mathrm{C}\right)\end{array}$ \\
\hline 100 & 10.5 & 6.4 \\
80 & 7.3 & 4.0 \\
60 & 4.0 & 2.2 \\
\hline
\end{tabular}

(2) Compared with A heat exchanger, B has a smaller bilateral temperature difference, which leads to its greater thermal conductivity and thermal capacity.

To sum up, B heat exchanger has a more superior thermal capacity and heat exchange efficiency than A. Thus, expensive though, imported heat exchanger is certainly worth it. Of course, the experiment in this paper only covers the test of thermal capacity, more analogous tests and more detailed consideration of some other factors is of great necessity wanting to get a full 
understanding of the difference about heat exchangers, such as structure, thickness, material, wave form, heat transfer area and thermal efficiency of the plate, as well as the calculation method.

\section{Acknowledgement}

These studies were financially supported by the Beijing Nova Program (XX2013011) and the Project of Beijing Municipal Party Committee Organization Department Outstanding Young Scholars. These supports are gratefully acknowledged.

\section{References}

1. I.M., Afonso,, H., Lubos, J.M., Maia, L.R., Melo. Heat transfer and rheology of stirred yoghurt during cooling in plate heat exchangers. $J$ Food Eng, 57: 179-187 (2003)

2. F.S.K., Wamakulasuriya, W,M., Worek. Heat transfer and pressure drop properties of high viscous solutions in plate heat exchangers. Int J Heat Mass Tran, 51: $52-67(2008)$

3. J.Y., Jeong, H.K., Hong, S.K., Kim, Y.T., Kang. Impact of plate design on the performance of welded type plate heat exchangers for sorption cycles. Int $J$ Refrig, 32: 705-711 (2009)

4. Z.N. Zhao. Effect of the corrugated inclination angle on heat transfer and resistance performances of plate heat exchangers. Petro-Chemical Equipment, 30, 1-3 (2001)

5. X.H. Ma, L. Lin, Z. Lan, Q.J. Yu, C.J. Yu, T. Bai, Y. Lin. The experimental research and thermodynamics analysis of plate heat exchanger performance under low Re. J Therm Sci Tech-jpn, 6(1): 38-44 (2007)

6. A., Muley. P.M., Manglik. Experimental Study of Turbulent Flow Transfer and Pressure Drop in a plate Heat Exchanger with Chevro Plates. J Heat Tran, 121(1): 110-117 (1999)

7. H.L., Ren, G.H., Zhang, Y.X., Zhang, K.Y., Ren, K., Fan, H.Z. Wang, J.W., Sun. The engineering research of plate heat exchanger on strengthening heat transfer of high viscosity fluid. Chemical industry design (Chinese), 19(2):20-31 (2009)

8. D.H. Shi. The aspects of plate heat exchanger. Public science (Chinese), 13: 26 (2007) 